\title{
A FENOMENOLOGIA COMO AVALIAÇÃO ESTÉTICA DA FOTOGRAFIA
}

\author{
THE PHENOMENOLOGY AS AESTHETIC EVALUATION OF PHOTOGRAPHY
}

Gustavo Luiz Pozza*

\begin{abstract}
RESUMO
Tendo como objetivo a avaliação das relações entre a estética e a fotografia, devido à singularidade desse meio entre as representações visuais, procura-se compreender o processo de apreciação estética da imagem através da fenomenologia. Podendo ser tomada tanto como obra de arte, quanto como um meio de comunicação, a fotografia se apresenta culturalmente em escala significativa, de maneira a que sua popularização a coloca constantemente em posição de avaliação e apreciação pelo espectador. Sua dependência a elementos existentes e, portanto, fotografáveis, também proporciona uma investigação com relação ao processo de captura como uma redução visual proposta pelo fotógrafo no instante em que atua. Assim, a construção do objeto estético pela obra fotográfica e a apreciação desse objeto pelo espectador demandam uma concepção e discussão melhor examinadas. A partir da compreensão dos mecanismos da comunicação visual, das propostas da filosofia fenomenológica e da possibilidade de avaliação estética da arte, foi possível obter dados relevantes tanto para o entendimento da percepção imagética pelo espectador quanto para um posicionamento crítico frente à arte. Esse enfoque teve como resultado a aplicação de uma metodologia de avaliação estética que permite ao espectador compreender, perceber, analisar e avaliar a obra de arte fotográfica. A obra avaliada por essa metodologia pode, dessa forma, ser dividida em conceitos constitutivos que, pelo viés fenomenológico, a permitem ser investigada de maneira a, subjetivamente, descrever a percepção do espectador e a influência dos elementos da linguagem visual na construção do discurso.
\end{abstract}

PALAVRAS-CHAVE: Fotografia. Arte. Estética. Fenomenologia. Percepção.

\begin{abstract}
Aiming at the evaluation of the relationship between aesthetics and photography, due to the uniqueness of the medium between visual representations, this paper seeks to understand the aesthetic appreciation process of an image through phenomenology. Being taken both as a work of art and as a communication medium, the picture appears in a culturally significant scale, so that its popularity constantly puts it on an evaluation position and appraisal by the viewer. Its dependence on the existing and therefore photographable elements also provides an investigation regarding the capture process as a visual reduction proposed by the photographer at the instant in which he operates. Thus, the construction of the aesthetic object of the photographic work and the appreciation of the object by the viewer demand a conception and discussion better examinated. From the understanding of the mechanisms of visual communication, the proposals of phenomenological philosophy and the possibility of aesthetic appreciation of art, it was possible to obtain relevant data to the understanding of imagery perception by the viewer as to a critical position towards art. This approach resulted in the application of an aesthetic evaluation methodology that allows the viewer to understand, perceive, analyze and evaluate the photographic work of art. The work evaluated by this method can thus be divided into constituent concepts wich, by the phenomenological bias, allow it to be investigated in order to subjectively describe the perception of the viewer and the influence of the elements of visual language in the construction of discourse.
\end{abstract}

KEYWORDS: Photography. Art. Aesthetics. Phenomenology. Perception.

\footnotetext{
* Mestre em Filosofia pela UCS (2015), possui graduação em Fotografia (2005 e 2013) e Especialização em Imagem Publicitária pela PUC-RS (2008).
} 


\section{Introdução}

O modo de produção de imagens fotográficas implica a construção, por isso, interpretação de um código visual que se enquadra nas análises semióticas. Assim, a imagem fotográfica pode ser compreendida como uma mensagem, uma declaração do fotógrafo sobre um tema. A esse testemunho imagético, une-se a possibilidade de apreciação estética, uma vez que o mesmo código que permite a mensagem, sendo visual, está sujeito a interpretações de composição e de estrutura de um objeto artístico.

Não se procura, certamente, propor que a fotografia detenha uma linguagem visual ou valores estéticos diferentes de outras manifestações artísticas, visto que isso implicaria a compartimentalização das artes visuais, ou ainda, de uma estética exclusiva à fotografia, bem como de uma arte fotográfica, o que significa negar as evoluções propiciadas pelo período pictorialista, que "permitiu à estética fotográfica ser considerada como uma persuasiva expressão de temperamento pessoal e escolha". (ROSEMBLUM, 1997, p. 332), assim, iniciando a aceitação da imagem fotográfica como manifestação da vontade criativa do artista e não fruto de um aparato tecnológico autômato e desprovido de possibilidades artísticas; ou negar teóricos, como Szarkowski (2009), para quem a "fotografia evoca a presença tangível da realidade" (p.12); por um lado, libertando a pintura da sua "obsessão realista" (BAZIN, 1991, p. 25), mas, por outro, confirmando a unidade da estética das manifestações artísticas visuais.

Contudo, espera-se construir uma análise que leve em conta características puramente fotográficas não pela sua gênese, mas pela sua inserção social e cultural, uma vez que detendo características particulares de associação com o real e de possibilidades de reprodução e alcance de massa, a fotografia insere em seu discurso elementos intangíveis que deturpariam o significado, caso não levados em conta.

\section{Estética fenomenológica e fotografia}

A fenomenologia pensa a estética pelo viés da percepção e da experiência. O conceito de experiência estética, com ênfase na experiência, coloca o espectador como participante do processo, por isso colaborador na construção da imagem e, por conta disso, da experiência. Perceber uma fotografia, um filme ou uma pintura são obviamente experiências distintas, 
todavia, a construção de um universo estético, de um "espaço pictórico". (ESCOUBAS, 2010, p. 249) é compartilhada por todas as formas de manifestação da arte visual. Essa manifestação pictórica construída em colaboração com o espectador deve ser entendida literalmente como um espaço, como um universo tridimensional, provido de tempo quando aplicável, em que acontece o diálogo entre a obra percebida e o ser que a percebe. Esse "mundo do objeto estético" (CASEY, 2010, p. 3) deixa de ser unicamente uma soma de objetos ou de elementos de linguagem visual para se tornar um universo aberto e sem limites. É dentro desse universo que acontece a experiência, por isso, é importante apresentar a diferenciação de Dufrenne entre a obra de arte e o objeto estético, pois enquanto a obra é o elemento físico da arte, a construção concreta da obra, o objeto estético é a obra como experienciada e percebida (CASEY, 2010, p. 4).

Como visto, não há uma percepção da obra, mas de seu objeto estético intrínseco, assim, quando tratando de linguagem visual, pode-se apresentar percepções das diferentes manifestações artísticas, sem que haja discrepância entre o resultado da experiência estética. Certamente, existem particularidades em cada meio - a abstração da pintura, o tempo do cinema, o realismo fotográfico - embora as fronteiras dessas particularidades se diluam numa leitura da evolução da linguagem da arte.

Para tanto, o foco permanecerá nas comunhões entre esses diferentes meios, mais do que suas particularidades. Assim, avaliando a resposta do espectador ao cinema, meio derivado da fotografia, com que apresenta mais similaridades do que diferenças, entende-se a construção do espaço de experiência estética:

O filme projetado na tela não é um objeto concluído, um ready-made aguardando passivamente para ser percebido pela consciência do espectador, mas em vez disso um outro anônimo, embora presente, que realiza sua própria atividade de ver, ouvir e mover-se. O filme é assim não apenas um objeto visto, mas, assim como o espectador, é também um sujeito que observa em si (DEL RÍO, 2010, p. 111).

Assim, para a fenomenologia, a construção bilateral da obra passa pela captura e exibição da imagem, por um lado, mas, principalmente, pela absorção da mensagem pelo espectador e sua resposta estética frente a ela.

Em relação à pintura, deve-se principiar por fazer uma ressalva significativa em relação à realidade possível, ou ainda, às possíveis realidades do tableau. Enquanto a fotografia, mesmo na sua situação contemporânea, suscetível a modificações, precisa do real para ser constituída, a pintura não detém essa conexão imediata com a realidade, como 
apontado anteriormente, portanto, aberta à abstração e ao irreal. Acima de tudo, é preciso lembrar que a pintura representa "as condições de visibilidade de acordo com suas modalidades históricas, e não as condições de representação do real”. (ESCOUBAS, 2010, p. 249), enquanto "não pode haver nunca uma fotografia completamente falsa" (CHEUNG, 2010, p. 259). Embora essa restrição, fotografia e pintura compartilham muitos dos outros elementos imagéticos e do mundo criado pelo objeto estético, sendo, sobretudo, a comunhão entre as duas manifestações que permite, de certa forma, que a pintura seja mais realista e a fotografia, mais abstrata.

A construção do objeto estético pela pintura serve, portanto, de fundamento para a avaliação de objetos construídos em quaisquer outras modalidades, principalmente, pela obrigatoriedade de construção desse espaço de contemplação, de grande contribuição para a fotografia, de onde, no seu surgimento, esperava-se apenas uma utilidade prática, como se à fotografia coubesse apenas registrar o mundo de maneira mais imaculada possível, sem a intervenção seja do fotógrafo, seja - fenomenologicamente - do espectador.

Posteriormente, a imagem produzida pelo aparelho atinge um caráter ontológico distinto da pintura e pode ser pensada independentemente, o que leva a uma avaliação do fenômeno da fotografia, mais precisamente do ato de fotografar, de ver o mundo unicamente como estético, contendo todas as outras avaliações possíveis sobre o que está sendo fotografado, numa epoché fotográfica. O fotógrafo deve ser capaz de reduzir o mundo a elementos visuais antes da captura da imagem, expressando na fotografia um código visual que propicie ao espectador uma apreciação direcionada do que foi fotografado. Fotografar é, acima de tudo ver por meio da câmera um mundo de formas, a priori, determinar o que fará parte do objeto estético inserido na obra fotográfica. "Ver fotograficamente é reduzir o mundo perceptivo a um mundo fotograficamente enquadrado". (CHEUNG, 2010, p. 262).

Essa apropriação do mundo que coloca a fotografia em uma posição de representação do visualmente existente, também traz o conceito de mimese e sua já conhecida implicação pejorativa na arte. Pode-se afirmar, categoricamente, a dependência da fotografia aos elementos fotografáveis no recorte a ser feito, o que se questiona na estética fenomenológica é o que significa referir-se a uma obra de arte como mimética.

Considerar-se a característica mimética da arte fotográfica como uma cópia imediata do fotografado é simplificar demasiadamente as possibilidades do suporte, sobretudo, estabelecer a arte como a capacidade de um artista, independentemente do suporte ou técnica escolhida, de representar a realidade da maneira mais fidedigna possível, o que eliminaria do 
espectro de possibilidades da arte todas as manifestações abstratas e não figurativas. Para Husserl, a ideia de uma arte que se preste a enganar o espectador na tentativa de substituir a coisa em si por sua representação, como no efeito trompe l'oeil, não passa de uma tentativa grosseira de divertimento (BROUGH, 2010, p. 281).

Assim, passa-se a considerar a mimese como a capacidade de qualquer representação visual de copiar a essência de um objeto, mais do que sua aparência, o que, inserido no universo fotográfico, significa afirmar que a obra de arte fotográfica precisa, além de representar o objeto pela sua aparência, também trazer elementos da ideia do que se deseja representar, para que seja efetivamente considerado como uma obra de arte.

Essa ideia, obrigatoriamente presente na arte, provém do autor, ou seja, a obra de arte origina-se dos atos intencionais de uma consciência criativa, sem a qual ter-se-ia uma representação factual, mas nunca intencional. A obra serve assim como uma ligação entre a experiência do espectador e a intenção do autor, pela criação de um ambiente perceptível que une a apresentação de um código visual com a imaginação de que o percebe. O objeto estético proveniente da obra - do elemento físico que a constitui - permite a construção de um universo sensível único, marcado pela (i) relação entre a representação e o objeto representado; (ii) a capacidade de representear elementos não visuais; e, (iii) a existência de um tempo e espaço próprios (NIELSEN, 2010, p. 351).

Sobre a representação (i), deve-se aqui apontar novamente para a característica de cópia do processo fotográfico, visto que ele não apenas procura representar algo a partir de uma codificação ou de similaridades, mas sim, que representa algo a partir dele mesmo, ou seja, que torna visível na obra a existência visual daquilo que representa. Essa representação do visível, ao invés de tornar redundante a representação, acaba por enfatizar o mundo perceptível ao “tornar visível o processo de ver” (BROUGH, 2010, p. 284), chamando atenção para o processo de percepção, principalmente, a partir da redução fotográfica, tornar visível o que não seria percebido. Longe de imitar o mundo sensível, o artista transforma o que vê na obra de arte, emprestando, assim, sua percepção ao espectador.

Ao se verificar a inserção do autor na construção do universo imagético, constata-se que, além dos elementos visuais captados pela sua percepção e representados na obra, outros elementos não visuais (ii) podem ser inseridos na representação. Surgem aqui elementos préimagéticos que definem a experiência sensível do espectador, marcando uma "singularidade sensível" (NIELSEN, 2010, p. 356) que permite a abertura de um campo infinito de interpretações. Como apresentado anteriormente, a obra está, dessa forma, aberta para a 
participação do espectador na sua construção, bem como para a inserção do autor como elemento decisivo na significação da experiência estética.

Husserl reconhece que obras de arte detêm uma estrutura tal que permite a construção de um "mundo ideal [...] no qual o espectador pode experienciar deleite estético" (BROUGH, 2010, p. 282), supondo uma consciência estética que esteja ligada à apreciação da representação no objeto estético, não interessado na existência do que ele representa fora da obra, ou seja, se, por um lado, Husserl afirma que o realismo da representação não é significativo para a apreciação e compreensão da obra; por outro, afirma também que existe um universo particular inserido no objeto estético que existe com seu próprio espaço e tempo, possivelmente, com valores próprios além dos estéticos. Assim, "mesmo que a realidade entre [nesse] mundo ficcional, não o faz de uma maneira que envolva a comparação entre a cópia e o original”. (BROUGH, 2010, p. 282).

Esse conceito de temporalidade e espacialidade próprias (iii) confere à obra de arte um caráter ontológico diverso da realidade, como posto por Ingarden, como uma construção intencional com um significado concreto que não corresponde a nada na realidade, que não tem como objetivo ser percebido como real no sentido de existente (NIELSEN, 2010, p. 352).

Dufrenne também se posiciona a favor da existência de um universo particular da obra de arte, rejeitando, inclusive, a mimese como imitação da realidade externa, ampliando a discussão para a existência de uma verdade própria da obra de arte, que não consiste em uma cópia da verdade do mundo exterior. Isso não sinaliza que as representações não tenham significado, mas que seu significado não corresponde nem se transfere para o original (BROUGH, 2010, p. 285), mesmo porque se deve levar em conta o caráter artístico de manifestações não representativas, como a arquitetura e a dança, que, contudo, detêm um significado que se apresenta para o espectador.

Embora a estética fenomenológica esteja fundamentada nas relações entre espectador, obra e autor, apresentadas até agora, não significa que sua orientação seja puramente subjetiva e dada apenas a descrições dos elementos que constituem uma representação. Lester Embree (2010, p. 215) propõe uma metodologia estética consistente, teorizada tanto a partir de Husser quanto dos teóricos que o seguem na tradição fenomenológica.

Embree apresenta como abordagem metodológica a divisão distinta da construção da estética fenomenológica em quatro procedimentos básicos: reflexão, intuição, análise e descrição; além de três outros procedimentos complementares: epoché psicológicofenomenológica, investigação regressiva e análise intencional de horizontes. 
Caracteriza como reflectiva, por um lado, atitude apreciativa, por outro, a obra de arte cuja atitude está direcionada. Assim, os encontros apreciativos com a obra formam, simultaneamente, a atitude estética ou apreciativa e a estipulação do objeto percebido como objeto apreciado. "Estética é, então, sobre a apreciação e o apreciado-como-apreciado" (EMBREE, 2010, p. 216).

A atitude apreciativa não diz respeito apenas ao espectador, mas também ao autor pelo processo metodológico. Embora não aconteça de uma maneira tão objetiva quanto a de quem percebe a criação de outro, a atitude estética do autor contempla a criação e a sugere como objeto estético, posto que o contrário implicaria uma não intencionalidade por parte do autor.

A intuição aparece como uma negação da argumentação no contexto dessa metodologia, e, seja essa intuição direta ou reflexiva, fundamenta-se tanto na percepção quanto na memória.

Um esteta fenomenológico não precisa recorrer com frequência um museu ou sala de concertos. Ele pode fazer muito não apenas com a memória, mas também com fotografias ou esboços, para não falar de partituras e gravações. Ainda assim, se diferenças aparecerem entre a obra-como-relembrada ou a obra-como-representada e a obra-como-percebida, cabe à ultima decidir (EMBREE, 2010, p. 217).

Assim, percepções anteriores, até mesmo de outros objetos estéticos - por comparação - constroem os juízos intuitivos do observador, por consequência, moldam sua percepção ou rememoração da obra. Complementária aos tópicos anteriores, a análise aparece como um instrumento para a materialização dessa intuição reflexiva da apreciação, pela concretização das experiências estéticas subjetivas provenientes desses elementos anteriores.

De maneira a construir um procedimento de análise interna da obra, subdivide-se essa etapa em três outros componentes postuláveis, a saber, dóxico, pático e práxico, cada um deles com valores positivo, negativo ou neutro. Então, os elementos constitutivos da obra de arte podem ser avaliados quanto a sua credibilidade - de crença na sua possibilidade de existência - que em sua predominância serão chamados de cognitivos, valores, que predominam como valorativos e usos, sendo volitivos ou práticos.

Quanto à descrição, entende-se como a apresentação de $o$ que algo é, antes que se pense em seu propósito ou causa, diferenciando-se assim da explicação, que apresenta fatos focando na razão de sua existência. Continuando a inter-relação entre os tópicos metodológicos, a descrição acompanha reflexão, intuição e análise na construção de uma rede de elementos investigativos da obra e do objeto estético. Toma importância na 
fenomenologia, ao propiciar a comparação entre experiências de um espectador com a de outros, visto que a descrição serve de ponte entre diferentes observadores que, ao descrever o que percebem, concretizam a análise/intuição/reflexão anterior.

O método proveniente desses elementos básicos da estética fenomenológica propicia a fundamentação da avaliação perceptiva, principalmente, a valoração da obra em questão. Iniciando pela reflexão, tem-se elementos para a intuição e para a análise, que se apresenta pela descrição do universo sensível da obra.

Iniciando três outras etapas metodológicas que, "podem não ser de tão fácil identificação", Embree (2010, p. 219) apresenta ainda uma epoché fenomenológicopsicológica que sugere que o espectador deva afastar-se de outras realidades que não a do universo estético da obra. Assim, propõe uma atitude apreciativa pura, sem a intervenção de relações de causa e efeito que, embora presentes, não são considerados. Essa visão pura permite a percepção das intencionalidades e da pretensão dos objetos encontrados, mesmo que sua existência seja impossível, contrária ou inversa a valores psicológicos do observador, no momento da avaliação.

Chama de investigação regressiva o processo de considerar o objeto percebido como um vestígio que leva à busca de outras percepções relacionadas a ele, identificando assim identidades e similitudes que constituem a síntese da obra. Iniciando pelo que está percebido na imagem, o espectador é levado a identificar o elemento constitutivo dessa representação, distinguindo o que está representado. Ocorre, assim, uma dupla valoração dos elementos percebidos, uma direcionada ao que é experienciado na obra e outra ao que está sendo representado, comprovada na existência de obras esteticamente agradáveis que representem acontecimentos ou situações perturbadoras.

Por fim, a análise intencional de horizontes propõe um procedimento que considera a diferença entre a apresentação de um elemento pela obra e como o mesmo elemento é presentificado na realidade, ou seja, chama de horizontes a possibilidade de apreensão do objeto em vários outros ângulos ou aspectos na realidade externa à obra. Não se trata de uma afirmação da limitação representacional de um dado processo, mas sim, da compreensão do objeto representado como sendo apenas uma das infinitas possibilidades representacionais.

Embora alguns aspectos da metodologia pareçam ambíguos ou subjetivos, a posição de Embree é de que, sendo a estética valorativa, o método fenomenológico proposto é normativo, portanto, aplicável à análise de obras de arte, assim, procura-se a seguir aplicar o método apresentado para avaliação de uma obra fotográfica. 


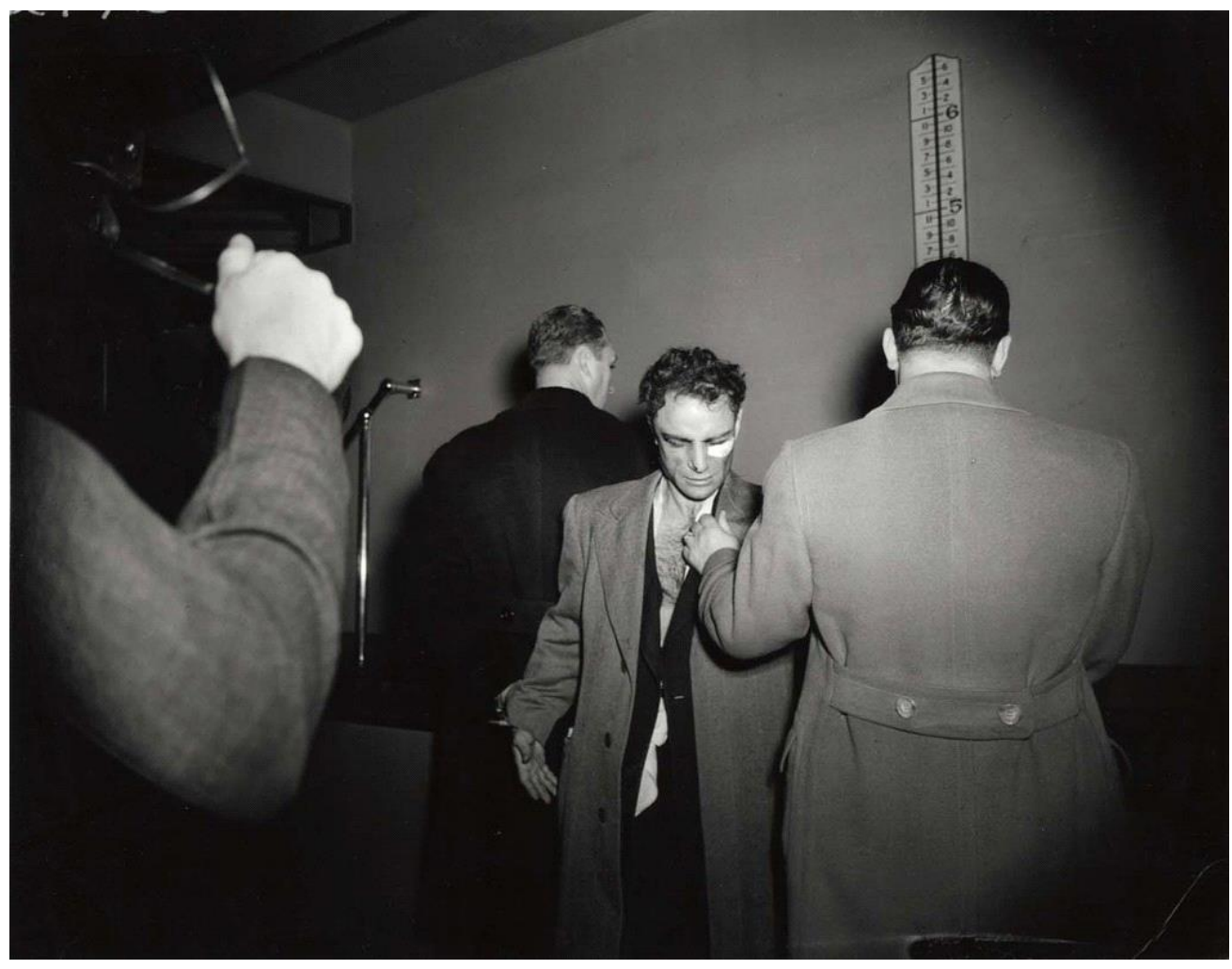

Figura 1 - Weegee - Cop Killer.

Fonte: Getty Museum

Tomando como objeto de análise uma fotografia policial elevada ao estado de obra de arte, principia-se por expor a transição desses estados de observação a que uma imagem pode ser submetida. Ter como função inicial a exposição de uma situação policial não impede que, deslocada de seu objetivo, a fotografia seja hoje considerada uma obra de arte, comprovadamente por estar na coleção do Metropolitan Museum, de Nova Iorque.

Essa mudança de estado atesta e fundamenta-se, simultaneamente, no primeiro elemento metodológico apresentado. A reflexão exigida pela atitude apreciativa muda o estado de percepção do observador, compreendendo um universo de uma complexidade maior ao de simples comunicação jornalística. Os personagens representados apresentam, uma vez que a atitude apreciativa também os remove de seu significado original, informações provindas unicamente de sua posição corporal e situação aparente na imagem.

Acontece, assim, o primeiro cruzamento entre os dois estágios iniciais dessa metodologia, a saber, reflexão e intuição, uma vez que a compreensão da atitude dos retratados depende unicamente, até agora, da compreensão do significado de elementos 
culturais e simbólicos. A roupa desarrumada do personagem central, juntamente com o curativo em sua face e a mão que o agarra pela gola do paletó, indica uma condição subjetiva que leva o observador a intuir seu estado como prisioneiro ou, pelo menos, que esteja sendo mantido diante das câmeras contra sua vontade.

Apesar de não ser o foco da imagem, a câmera à esquerda reforça a relutância desse personagem em se manter nessa posição, ainda mais pelos dois outros homens identificáveis na imagem estarem voltados de forma a não serem fotografados. A fotografia apresenta-se aqui como uma punição a esse homem, que ironicamente - uma das características do autor tem sua imagem e a imagem da imagem sendo capturadas simultaneamente, numa dupla penitência.

A cena pressupõe a rememoração, por parte do espectador, de situações de opressão, violência e punição vivenciadas ou percebidas por ele, sem as quais o significado desses elementos poderia passar despercebido. Assim, a gravidade e a dor do ferimento no rosto, a pressão com que ele é contido e a humilhação vivenciada são percebidas pelo espectador a partir de outras situações, tornando-o parte da cena que presencia, principiando a construção de espaço imagético desse objeto estético.

No detalhe analítico dessa metodologia fenomenológica, aparece a percepção de valores dóxicos, páticos e práxicos, como demonstrado anteriormente, que precisam ser considerados como positivos, negativos ou neutros. Avaliar a qualidade dóxica da imagem fotográfica, tratando nesse contexto da "característica de veracidade" (EMBREE, 2010, p. 217), pode parecer um tanto desnecessário, posto o enquadramento indicial da fotografia, entretanto, afere-se aqui apenas a percepção do observador, não a existência ou não do fato retratado. A fotografia policial, bem como suas variações videográficas mais atuais, sustentase, sobretudo, pelo choque causado no espectador ao presenciar uma cena que não seja de sua vivência cotidiana. Imagens de crimes, fome e calamidades apelam substancialmente a observadores não envolvidos cotidianamente nessas ocorrências. Assim, a imersão nesse universo policial apresentado na imagem, bem como a fotografia como prova - não a que se tem acesso, mas a do fotógrafo presente na cena - reforçam o antagonismo entre a realidade percebida e a realidade representada.

Num segundo estágio, procurar-se-ia vincular valores a essa imagem, processo particularmente subjetivo, que depende fundamentalmente da percepção em que o observador está inserido. Mais do que associar valores morais positivos ou negativos, remete-se aqui à dependência peirceana, apresentada no capítulo anterior entre a ética e a estética, pois se a 
valoração estética da imagem está construída principalmente pela complexidade da mensagem, dos elementos histórico-sociais e a empatia do espectador pelos personagens retratados, sua predominância valorativa está no aparente conflito entre polos morais e jurídicos, fazendo com que a curiosidade do observador o coloque empaticamente tanto na posição do policial quanto do preso, sentindo e percebendo simultaneamente os dois mundos, num questionamento moral proveniente do universo da obra.

Conclui-se a etapa analítica pela verificação dos componentes práxicos da obra, o que depende de maneira imprescindível da aplicação a que se destina essa imagem. Considerar-seá, para a efetividade dessa análise, a fotografia em seu contexto original, visto que avaliar a praxicidade de sua mensagem artística seria um tanto subjetivo e até mesmo vago. Como mensagem jornalística, a fotografia de Weegee apresenta ao espectador a cena de uma prisão. Sem informações que a contextualizem, subtraídas propositalmente também da análise metodológica até o presente momento, sua função fica comprometida pela ambiguidade da situação apresentada.

Partindo para os tópicos complementares da metodologia, a epoché de avaliação da obra de arte propõe o afastamento do espectador de quaisquer fundamentos teóricos da realidade, permitindo a apreciação da obra sem que se leve em conta conceitos e regras $a$ priori. Na imagem em questão, esse afastamento permite a compreensão da imagem como linguagem visual, favorecendo a compreensão de elementos não verbais que, pela construção da composição pelo autor, intensificam a percepção da mensagem pretendida.

A área desfocada na esquerda da imagem, compreendendo o braço do fotógrafo e parte de sua câmera, direciona a visão do observador para o centro da fotografia, movimento reforçado pela presença de uma vinheta nas bordas da imagem. A fila de homens ao centro sugere uma repetição do mesmo elemento, dando a percepção de profundidade, porém, destacando o elemento que pode ser visto de frente. O rosto posicionado no centro geométrico da cena indica o tema principal e provoca o espectador a compreender o acontecimento registrado.

A sugestão de um recorte que elimine a área a esquerda demonstra como o desequilíbrio causado pela diferença de dimensão entre os homens ao centro e o braço mais próximo da câmera perturba a observação da imagem, dando tanto uma sensação de confusão quanto de dinâmica. A imagem recortada parece estática e equilibrada, servindo como uma antítese à imagem anterior. 


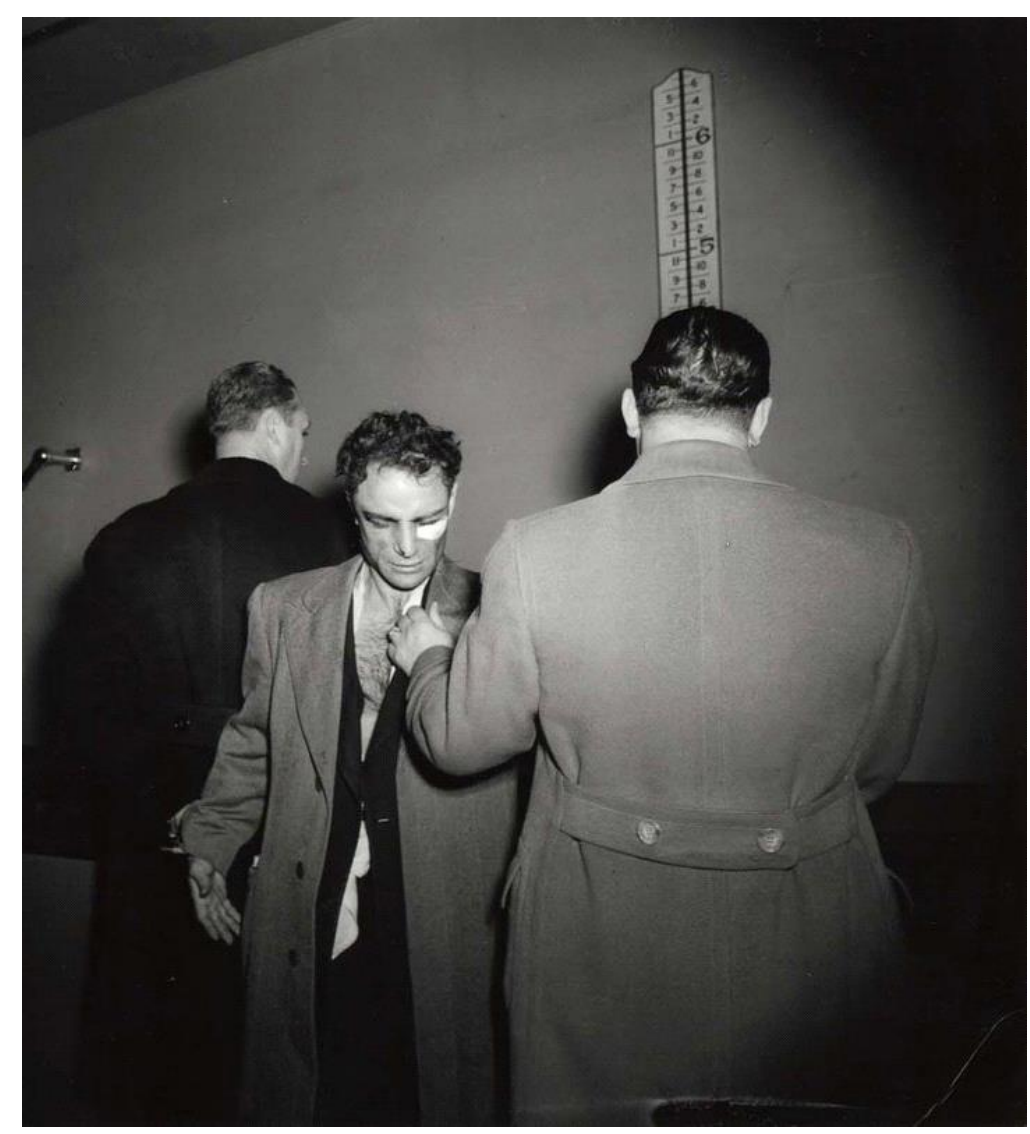

Figura 2 - Weegee - Cop Killer - Recorte.

Fonte: Getty Museum.

A investigação regressiva propõe considerar a imagem como um vestígio de algo. No caso da fotografia, principalmente, em se tratando de uma fotografia jornalística originalmente, o acesso à informação é facilitado. O homem ao centro, anteriormente percebido como um prisioneiro ou, ao menos, alguém mantido em frente à câmera contra sua vontade, é um criminoso que acabara de ser preso pela polícia de Nova Iorque, acusado de ter assassinado um policial em uma tentativa frustrada de assalto. $\mathrm{O}$ autor registra a imagem no exato momento em que sua fotografia estava também sendo feita pelo fotógrafo da polícia local. Os dois homens que contêm o prisioneiro, supostamente policiais, estão com o rosto voltado para a parede de modo a que não fossem identificados, numa atitude característica da profissão de manter a privacidade dos policiais.

Os dados que contextualizam a fotografia servem também para auxiliar a compreensão do momento e do local em que foi realizada. Intui-se que um prisioneiro esteja sendo fichado dentro de uma delegacia, dando forma tanto ao corrimão visto ao fundo quanto à régua na parede utilizada para marcar a altura do suspeito. A agressividade da ação policial toma forma 
pelo desalinho do prisioneiro - contraposto à aparente impecabilidade dos policiais com a roupa e o cabelo arrumados - e pelas marcas de ferimentos no rosto.

A verificação dos elementos apresentados até esse ponto culmina na análise intencional de horizontes, ou seja, em uma fotografia, a percepção do espaço sugerido não presente na imagem. A construção subjetiva de um espaço pictórico em que o observador se insere leva à finalização desses elementos ausentes pela imaginação ou recordação. Partindo da indiscutível adição de um corpo ao braço que fotografa, além do corpo do próprio autor da fotografia, percebe-se a simetria entre os fotógrafos e os policiais, formando uma estrutura ao redor do preso, que agora não ocupa apenas o centro geométrico da imagem, mas também do espaço físico da cena. Subjetivamente, uma vez que a percepção agora se fundamenta unicamente nas experiências do espectador, a sala da delegacia pode estar vazia ou lotada com outros repórteres e policias, o que acrescenta a imagem sensações não visuais como o barulho - ou silêncio - o esbarrar de corpos, a temperatura da sala. Nenhum desses elementos aparece ou é sugerido pelo autor, entretanto, embora a análise aconteça de forma diferente caso outra pessoa a faça, percebe-se um espaço imagético claro, vivo e consistente.

Retomando o início da aplicação dessa metodologia, verifica-se o impacto da atitude reflexiva em par com a complexidade da mensagem proposta intencionalmente pelo autor da fotografia na construção de uma obra fotográfica, que se destaca pelo envolvimento e participação do espectador na sua formulação narrativa.

A repetição da metodologia seja por outro espectador, seja em outro momento, proporcionará resultados diversos de percepção. Para a estética fenomenológica, tão importante quanto a obra de arte a ser apreciada, é a percepção do espectador, de forma que a materialidade da obra é "impessoal e independente" (NIELSEN, 2010, p. 352) estando aberta a uma análise compreensiva por parte do observador.

\section{Conclusão}

A metodologia apresentada, em concordância com as propostas da corrente fenomenológica, apresenta uma substancial capacidade de avaliação dos elementos constituintes da experiência estética e, principalmente, proporciona uma capacidade de validação ou, ao menos, de mensuração, das especificidades estéticas de obras fotográficas. Possibilita também instrumentos para a verificação do cunho artístico das obras a serem 
debatidas, uma vez que o caráter estético e a legitimidade artística de uma fotografia são significativos na maneira como a mensagem representada é percebida.

\section{Referências}

BAZIN, André. O cinema: Ensaios. São Paulo: Brasiliense, 1991.

BROUGH, John. Representation. In: SEPP, Hans; EMBREE, Lester. The handbook of phenomenological Aesthetics. New York: Springer, 2010. p. 281-286.

CASEY, Edward S. Aesthetic Experience. In: SEPP, Hans; EMBREE, Lester. The handbook of phenomenological Aesthetics. New York: Springer, 2010. p. 1- 8.

CHEUNG, Chan-Fai. Photography. In: SEPP, Hans; EMBREE, Lester. The handbook of phenomenological Aesthetics. New York: Springer, 2010. p. 259-264.

EMBREE, Lester. Methodology. In: SEPP, Hans; EMBREE, Lester. The handbook of phenomenological Aesthetics. New York: Springer, 2010. p. 215-221.

ESCOUBAS, Eliane. Painting. In: SEPP, Hans; EMBREE, Lester. The handbook of phenomenological Aesthetics. New York: Springer, 2010. p. 249-254.

GETTY

MUSEUM.

Disponível

em:

$<$ http://www.getty.edu/art/collection/objects/36576/weegee-arthur-fellig-cop-killer-americannegative-january-16-1941-print-about-1950/> Acesso em: 19 ago 2015.

NIELSEN, Cathrin. Work of Art. In: SEPP, Hans; EMBREE, Lester. The handbook of phenomenological Aesthetics. New York: Springer, 2010. p. 351-357.

ROSENBLUM, Naomi. A World History of Photography. New York:Abbeville press, 1997.

SZARKOWSKI, John. The Photographer's Eye. New York: Museum of Modern Art, 2009. 